\title{
INSTRUMENTOS DISPONÍVEIS NO NOVO CÓDIGO DE PROCESSO CIVIL PARA A EFETIVAÇÃO DA UNIFORMIZAÇÃO DOS PROCEDENTES
}

INSTRUMENTS AVAILABLE IN THE NEW CIVIL PROCEDURE CODE FOR THE ENFORCEMENT OF THE UNIFICATION OF THE PRO-

CEEDINGS

\section{Angela de Lara Joviatti ${ }^{1}$}

ISSUE DOI: $10.21207 / 1983.4225 .353$

\section{RESUMO}

A finalidade do presente trabalho é informar as características concernentes ao sistema jurídico, common law. Abordar o contexto histórico e cultural no qual o instituto foi estabelecido. Conceituar o instituto dos precedentes. Abordar os instrumentos inseridos no novo Código de Processo Civil, Lei 13.105/15, para garantir a efetiva uniformização das decisões no ordenamento jurídico brasileiro. Para tanto, abordaram-se os seguintes institutos: Incidente de Assunção de Competência, Incidente de Resolução de Demandas Repetitivas, Embargos de Divergência e Recursos Repetitivos Extraordinário e Especial. A metodologia empregada na confecção do presente estudo foi a de revisão literária, utilizando-se para tanto de apontamentos doutrinários, de artigos científicos e da análise da Lei 13.105/15, obtendo-se como resultado posicionamentos críticos e favoráveis à aplicação do instituto.

1 Graduada em Direito pela UNIFOZ - Sociedade de Educação Três Fronteiras, pósgraduada em Processo Civil pela LFG/Anhanguera. 
Palavras-Chave: Common Law. Civil Law. Precedentes. Incidente de Assunção de Competência. Incidente de Resolução de Demandas Repetitivas. Embargos de Divergência. Recursos Repetitivos Extraordinário e Especial.

\section{ABSTRACT}

The purpose of this paper is to inform the characteristics of the legal system, common law. Address the historical and cultural context in which the institute was established. Conceptualize the institute of precedents. Address the instruments included in the new civil process code, Law $13,105 / 15$, to ensure the effective standardization of decisions in the Brazilian legal system. To this end, the following institutes were addressed: Incident of Assumption of Competence, Incident of Resolution of Repetitive Claims, Embargos de Divergencia and Repetitive ResourcesExtraordinary and Special. The methodology used in the preparation of the present study was the one of literary revision, using for both doctrinal notes, scientific articles and the analysis of Law 13,105 / 15, obtaining as a result critical and favorable positions to the application of the institute.

Keywords: Common Law. Civil Law. Precedents. Incident of Assumption of Competence. Repetitive Demands Resolution Incident. Embargoes of Divergence. Extraordinary and Special Repetitive Resources.

\section{INTRODUÇÃO}

Atualmente há dois sistemas jurídicos existentes, o common law e o civil law, sistemas completamente opostos que se originaram em circunstâncias distintas.

Neste estudo realizou-se um regaste histórico com a finalidade de demonstrar as particularidades nas quais estão embasadas os dois sistemas, ou seja, a cultura dos usos e costumes e a codificação das condutas sociais.

Para que o instituto dos precedentes fosse melhor compreendido há a explanação do conceito do que vem a ser precedente, técnica que possui como principal objetivo o direcionamento para decisões futuras e analógas e que busca evitar divergências nas decisões judiciais. 
O objetivo central do presente estudo é apresentar os diversos instrumentos processuais inseridos no Código de Processo Civil, Lei $13.105 / 15$, os quais preveem o estabelecimento à vinculação obrigatória da jurisprudência nas decisões do judiciário, instrumentos estes capazes de efetivar a uniformização dos julgados no ordenamento jurídico brasileiro.

Os instrumentos inseridos no novo Código de Processo Civil e que foram abordados no presente trabalho foram os seguintes: Incidente de Assunção de Competência, Incidente de Resolução de Demandas Repetitivas, Embargos de Divergência e Incidente de Demandas Repetitivas em Recurso Extraordinário e Recurso Especial.

Houve uma breve síntese de como se dá o processamento de cada um desses instrumentos, abordou-se a respeito de seus legitimados ativos, de seu cabimento, do momento processual para sua proposição, e de seus pressupostos e requisitos processuais.

Foram expostas as argumentações dos frutos que serão colhidos com a implementação da uniformização das decisões. Houve ainda o apontamento dos posicionamentos favoráveis e contrários à sua efetivação.

De grande relevância é a abordagem do presente tema em virtude da reflexão sobre a possibilidade do instituto trazer segurança jurídica, previsibilidade e celeridade ao processo, princípios fundamentais que, se efetivados, irão ao encontro de uma estabilidade jurídica almejada por todos.

\section{SOBRE OS PRECEDENTES}

\subsection{CONTEXTO HISTÓRICO DOS PRECEDENTES}

O common law é um sistema de direito originário dos povos barbáros e é consuetudinário, ou seja, baseado nos usos e costumes de cada povo e geralmente não escrito.

Nas palavras de Vitor Galvão Fraga, os povos bárbaros ocuparam as ilhas britânicas e desconheciam a estrutura de um Estado, 
viviam em agrupamentos, prevalecendo a tradição dos dominantes em cada um deles. ${ }^{2}$

Segundo Fernando Silva Soares ${ }^{3}$, após a conquista da Inglaterra pela Normandia em 1875, é que nasce o common law propriamente dito, pois as tradições aplicadas a cada grupamento foram substituídas pela "lei comum". ${ }^{4}$

A Inglaterra criou os denominados Tribunais de Westminster e estes criavam o common law (a lei comum a todos, denominação utilizada pelo rei em repugnação aos direitos costumeiros dos povos originários). ${ }^{5}$

Entretanto, os tribunais não eram acessíveis a todos: aqueles que desejavam que seu caso fosse levado até eles - deveriam solicitar a concessão de um writ do chanceler e nos julgamentos prevalecia a máxima Remedies Preceed Rights, ou seja, primeiramente era necessário toda uma série de formalismos para então a sentença ser proferida, assim nascendo a jurisprudência com normas sólidas, esboçando os precedentes como fonte principal de direito. ${ }^{6}$

Luiz Guilherme Marinoni afirma que com o objetivo de conter os arbítrios do poder absolutista do rei inglês, o parlamento, com a Revolução Gloriosa de 1688, esteve ao lado dos juízes e por diversas vezes os dois poderes chegaram a se misturar. $\mathrm{O}$ intuito da revolução não foi o de subjugar os juízes à prevalência das leis e sim o de expor a força do parlamento diante do poder real e, com isso, a afirmação do commom law contra o rei. ${ }^{7}$

Neste sentido, as normas elaboradas pelo parlamento estavam inseridas no common law, na busca pela afirmação dos direitos e liberdades do povo inglês contra o rei.

\footnotetext{
2 FRAGA, Vitor Galvão. O sistema do Common Law. Jus Navigandi, Teresina, ano 17, n. 3394, 16 out. 2012. Disponível em: <http://jus.com.br/revista/texto/22816>. Acesso em: 5 jul. 2015.

${ }^{3}$ Ibidem.

${ }^{4}$ Ibidem.

${ }^{5}$ Ibidem.

${ }^{6}$ Ibidem.

${ }^{7}$ MARINONI, Luiz Guilherme. Aproximação crítica entre as jurisdições de civil lawe de common lawe a necessidade de respeito aos precedentes no brasil.[pdf]. Disponível em: <http://www2.trf4.jus.br/trf4/upload/editor/rlp_Luis_Marinoni.pdf>. Acesso em 13 abr. 2015.
} 
A Revolução Gloriosa de 1688, na Inglaterra, não teve como significado, portanto, a submissão do monarca às normas produzidas pelo parlamento, mas ao direito inglês em toda a sua integralidade. ${ }^{8}$

Também as colônias pertencentes à Inglaterra passaram a se submeter ao direito inglês, de amplitude maior que a mera legislação inglesa em si, firmando sua submissão à common law.

Desta forma, a Revolução Gloriosa não teve em sua essencialidade um espírito revolucionário, pois não desejou romper com o passado, não sendo seu escopo destruir o direito já existente, mas, ao contrário: confirmá-lo e fazê-lo valer contra um rei que não o respeitava. ${ }^{9}$

\subsection{CONCEITO DE PRECEDENTE}

Precedente é a decisão judicial extraída a partir de um caso concreto, cuja essência possa servir como direcionamento para o julgamento de casos análogos futuros. No entanto, não é toda e qualquer decisão que é tomada como precedente, somente aquelas que têm força de serem tomadas como paradigmas para nortear os jurisdicionados e os magistrados. ${ }^{10}$

É comum falar em precedente e stare decisis como termos sinônimos, como afirma Neil Duxbury: "stare decisis comporta o pensamento de que as decisôes anteriores devem ser seguidas quando os mesmos pontos surgem novamente em juízo, sendo os juízes do common law obrigados a seguir os precedentes". ${ }^{11}$

\footnotetext{
${ }^{8}$ MARINONI, Luiz Guilherme. Aproximação crítica entre as jurisdições de civil lawe de common lawe a necessidade de respeito aos precedentes no brasil.[pdf]. Disponível em: <http://www2.trf4.jus.br/trf4/upload/editor/rlp_Luis_Marinoni.pdf>. Acesso em 13 abr. 2015.

${ }^{9}$ Ibidem.

10 RAMOS, Vinícius Estefaneli. Teoria dos precedentes judiciais e sua eficácia no sistema brasileiro atual. Disponível em: http://jus.com.br/artigos/24569/teoria-dosprecedentes-judiciais-e-sua-eficacia-no-sistema-brasileiro-atual. Acesso em: 02 set. 2015. ${ }^{11}$ ODAHARA, Bruno Periolo. Um rápido olhar sobre o staredecisis. Processos Coletivos Revista Eletrônica, Porto Alegre, vol. 2, n. 3, 01 jul. 2011. Disponível em: <http:/www.processoscoletivos.net/revista-eletronica/25-volume-2-numero-3-trimestre01-07-2011-a-30-09-2011/132-um-rapido-olhar-sobre-o-stare-decisis>. Acesso em: 24 set. 2015.
} 
Cabe ressaltar que a força vinculante dos precedentes se justifica pela obediência hierárquica de instâncias inferiores às instâncias superiores e que operam também de forma horizontal. ${ }^{12}$

O termo stare decisis tem sua origem no latim e originariamente se dizia: stare decisis et non quieta movere, ou seja, "mantenha aquilo que já foi decidido e não altere aquilo que já foi estabelecido."13

No entanto, há divergência sobre este entendimento. Frederick Schauer denota distinções entre os dois termos empregados no sistema do common law e dá a seguinte definição:

Tecnicamente, a obrigação de uma corte de seguir decisões prévias da mesma corte é referida como stare decisis e o termo mais abrangente precedente é usado para referir tanto à stare decisis, quanto a obrigação de uma corte inferior de seguir decisões de uma superior. ${ }^{14}$

Realizada a conceituação de precedentes, necessário se faz apontar instrumentos em nosso ordenamento jurídico intuindo torná-lo obrigatório.

\section{INSTRUMENTOS PARA UNIFORMIZAÇÃO DOS PRECEDENTES NO BRASIL}

O novo Código de Processo Civil, em seu artigo 926 e seguintes, inova ao trazer diretrizes para a uniformização da jurisprudência com o objetivo de alcançar sua estabilidade, integralidade e coerência.

12 ODAHARA, Bruno Periolo. Um rápido olhar sobre o staredecisis. Processos Coletivos Revista Eletrônica, Porto Alegre, vol. 2, n. 3, 01 jul. 2011. Disponível em: $<$ http://www.processoscoletivos.net/revista-eletronica/25-volume-2-numero-3-trimestre01-07-2011-a-30-09-2011/132-um-rapido-olhar-sobre-o-stare-decisis >. Acesso em: 24 set. 2015.

13 Ibidem.

${ }^{14}$ Ibidem. 
Dessa forma os tribunais não deverão permitir divergências internas sobre questões jurídicas idênticas, trazendo coerência ao sistema. ${ }^{15}$

Muito além de edição de súmulas, a norma tem a presunção de que haja a adequada referência aos fatos determinantes que formaram a sua criação. ${ }^{16}$

A exigência da estabilidade está intimamente ligada ao dever de respeito aos precedentes preexistentes e a necessidade de fundamentação adequada para o caso de sua não aplicação em razão de sua distinção ou superação. ${ }^{17}$

Há a possibilidade de afastamento das teses firmadas nos tribunais superiores do país através das técnicas ora expostas e seu processamento está disciplinado no artigo 927 do novo Código de Processo Civil. $^{18}$

Diante disto, o novo diploma traz alguns instrumentos que poderão ser aplicados para o alcance desta uniformização, sendo alguns deles: Incidente de Assunção de Competência (art. 947), Embargos de Divergência (art. 1.043 e ss.), Incidente de Resolução de Demandas Repetitivas (art.976 e ss.), Recursos Repetitivos Extraordinário e Especial (1.036 e ss).

\subsection{O INCIDENTE DE ASSUNÇÃO DE COMPETÊNCIA E O INCIDENTE DE RESOLUÇÃO DE DEMANDAS REPETITIVAS}

A Assunção de Competência está prevista no artigo 947 do Código de Processo Civil de 2015; o instituto prevê que se houver relevante questão de direito, o relator, de ofício ou a pedido da parte,

\footnotetext{
15 MANZELLO, André. Jurisprudência Lotérica. JusBrasil Notícias. Out 2015. Disponível em <http://andrecm.jusbrasil.com.br/noticias/222840959/jurisprudencia-loterica? ref=topic_feed $>$. Acesso em: 02 nov 2015.

16 Ibidem.

${ }^{17}$ Ibidem.

18 BRASIL. Lei $n^{0}$ 13.105. 16 de março de 2015. Institui o Código de Processo Civil.Disponível em <http://www.planalto.gov.br/ccivil_03/_Ato2015-2018/2015/Lei/L1310 5.htm> Acesso em: 07 nov. 2015.
} 
poderá propor que a lide seja julgada pelo órgão colegiado, na forma que o regimento interno indicar.

O instituto terá cabimento em recursos, remessas necessárias e processos de competência originária do tribunal. Caso o órgão colegiado entenda que está contida matéria de interesse público para a propositura da Assunção de Competência, julgará o feito.

O acórdão proferido em Assunção de Competência terá o condão de vincular todos os juízes e os órgãos fracionários vinculados ao tribunal, excetuando-se apenas os casos em que houver revisão de tese.

Com a aplicação deste instrumento se pretende que, ocorrendo relevante questão de direito, previna-se ou haja composição das divergências entre as câmaras ou turmas recursais de um mesmo tribunal.

A diferença significativa entre o instituto da Assunção de Competência e o Incidente de Resolução de Demandas Repetitivas é que para a aplicação deste último há a necessidade de que a questão apresente múltipla repetição, sendo que no primeiro inexiste este requisito. ${ }^{19}$

Os demais requesitos para a propositura do Incidente de Resolução de Demandas Repetitivas são semelhantes aos que devem estar presentes no IAC, ou seja, a questão abordada deve ser de repercussão geral e há que conter relevante matéria de direito na questão controvetida.

O artigo 976 do novo Código de Processo Civil estabelece que para o cabimento do IRDP - Incidente de Resolução de Demandas Repetitivas, é necessário que haja simultaneamente a repetição de processos em que existam unicamente questões de direitos controvertidas e cujo risco é de afronta à isonomia e à segurança jurídica. ${ }^{20}$

No entanto, há outras questões importantes no IRDP a serem abordadas, sendo uma delas o estabelecimento de que mesmo havendo abandono ou desistência do processo não há óbice para que o exame do mérito do incidente seja realizado, ou seja, o órgão colegiado, se julgar necessário analisará a questão de direito controvertida.

\footnotetext{
${ }^{19}$ MANZELLO, André. Jurisprudência Lotérica. JusBrasil Notícias. Out 2015. Disponível em <http://andrecm.jusbrasil.com.br/noticias/222840959/jurisprudencia-loterica?r ef=topic_feed $>$. Acesso em: 02 nov 2015.

${ }^{20}$ BRASIL. Lei $\mathbf{n}^{\mathbf{0}}$ 13.105. 16 de março de 2015. Institui o Código de Processo Civil.Disponível em <http://www.planalto.gov.br/ccivil_03/_Ato2015-2018/2015/Lei/L1310 5.htm> Acesso em: 0 nov. 2015.
} 
Outro ponto é a definição de não cabimento do instituto em questões em que os tribunais superiores já tenham afetado recurso para a definição da tese sobre a questão de direito material ou processual contida no pretenso IRDP. ${ }^{21}$

Importante destacar que não haverá custas processuais para a proposição do IRDP e que o conjunto de sujeitos ativos para sua proposição é amplo, podendo figurar como proponente o juiz ou o relator, de ofício, as partes por petição, o Ministério Público e a Defensoria também por petição. ${ }^{22}$

O julgamento do instituto deve ser realizado por órgão colegiado, conforme as definições contidas no regimento interno do tribunal afeto e o acórdão dever ter específica e ampla divulgação, devendo ser criado banco de dados eletrônico para tal finalidade junto ao Conselho Nacional de Justiça. Este banco de dados deverá conter primordialmente os fundamento determinantes da decisão e os dispositivos normativos relacionados a ele. ${ }^{23}$

Após a análise dos pressuspostos para admissibilidade do IRDP, o relator suspenderá os demais processos pendentes que tramitam no Estado ou na região, poderá requisitar informações dos processos que tramitam nos órgãos vinculados, bem como as ações suspensas e intimará o Ministério Público se quiser se manifestar. ${ }^{24}$

O instituto ora estudado é abrangente também nas questões relativas às consultas públicas, nas quais o juiz poderá ouvir as partes ou pessoas conhecedoras da matéria objeto da controvérsia para opinirem sobre o caso. ${ }^{25}$

Salienta-se que o prazo máximo para o julgamento do incidente é de 01 (um) ano; se não for concluido até este prazo, as ações individuais ou coletivas suspensas voltarão a seguir o procedimento originário para que sejam conclusas. ${ }^{26}$

${ }^{21}$ BRASIL. Lei $\mathbf{n}^{\mathbf{0}}$ 13.105. 16 de março de 2015. Institui o Código de Processo Civil.Disponível em <http://www.planalto.gov.br/ccivil_03/_Ato2015-2018/2015/Lei/L1310 5.htm> Acesso em: 07 nov. 2015.

22 Ibidem.

${ }^{23}$ Ibidem.

${ }^{23}$ Ibidem.

24 Ibidem.

${ }^{25}$ Ibidem.

${ }^{26}$ Ibidem. 
No entanto, ocorrendo o julgamento do incidente pelo órgão colegiado, sua tese jurídica deverá ser aplicada a todos processos individuais ou coletivos que versarem sobre matéria idêntica ao IRDP e que tramitam na mesma área de jurisdição do tribunal e aos casos futuros que da mesma maneira tiverem matéria idêntica concernente ao IRDP já julgado pelo órgão colegiado. ${ }^{27}$

Não havendo observação e aplicação da tese definida no acórdão a matérias semelhantes ao IRDR, caberá reclamação. ${ }^{28}$

\subsection{EMBARGOS DE DIVERGÊNCIA}

Os embargos de divergência estão previstos nos artigos 1043 e 1044 no Código de Processo Civil de 2015 e são aplicáveis a acórdãos de órgãos fracionários sem sede de Recursos Extraordinários e Recursos Especiais que divergirem em suas decisões em casos específicos, sendo eles: ${ }^{29}$

Da decisão contida no acórdão que contrariar outro órgão do mesmo tribunal, sendo os acórdãos, embargado o paradigma de mérito, relativos a divergência concernente a juízo de admissibilidade, ou de um acórdão de mérito e outro que não tenha conhecimento do recurso, embora tenha apreciado o mérito. ${ }^{30}$

O outro cabimento do instituto que extrapola os recursos em sede de Tribunais Superiores é concernente a decisões nos processos de competência originária que contenham divergência do julgamento de qualquer outro órgão do mesmo tribunal. ${ }^{31}$

Outro aspecto importante que se pode ressaltar na seara da interposição dos embargos de divergência é que estes poderão conter matérias tanto de direito material qual de direito processual. ${ }^{32}$

${ }^{27}$ BRASIL. Lei $\mathbf{n}^{\mathbf{0}}$ 13.105. 16 de março de 2015. Institui o Código de Processo Civil.Disponível em <http://www.planalto.gov.br/ccivil_03/_Ato2015-2018/2015/Lei/L1310 5.htm> Acesso em: 07 nov. 2015.

${ }^{28}$ Ibidem.
${ }^{29}$ Ibidem.
${ }^{30}$ Ibidem.
${ }^{31}$ Ibidem.
${ }^{32}$ Ibidem. 
Ao tribunal está vedado, de forma expressa, inadmitir os embargos de divergência com base em fundamento genérico de que as situações fáticas são distintas, sem realizar a demonstração de tal distinção. ${ }^{33}$

Diante de todos os institutos aqui apresentados, certifica-se claramente $\mathrm{o}$ desejo do legislador brasileiro em disponibilizar instrumentos ao Pode Judiciário para que as decisões de casos análogos sejam julgadas de forma idênticas, objetivando o alcance da segurança jurídica e a confiabilidade das decisões no âmbito do judiciário brasileiro.

\subsection{RECURSOS REPETITIVOS EXTRAORDINÁRIO E ESPECIAL}

Os Recursos Repetitivos Extraordinário e Especial são instrumentos idealizados pelo legislador brasileiro para que questões semelhantes sejam julgadas e tratadas de forma idênticas.

No novo Código de Processo Civil, nos artigos 1.036 à 1.040 está estabelecido o procedimento a ser adotado caso haja multiplicidade de recursos extraordinários ou especiais que contenham fundamentação de direito idênticas. ${ }^{34}$

A seguir, serão expostas as peculiaridades que se apresentam com maior relavância no processamento de tais recursos repetitivos.

Havendo multiplicidade de RE e Resp o presidente ou o vicepresidente de tribunal de justiça ou tribunal regional federal selecionará 2 (dois) ou mais recursos representativos da controvérsia que serão encaminhados ao Supremo Tribunal Federal ou ao Superior Tribunal de Justiça, conforme o caso, e determinará a suspensão de todos os processos pendentes em trâmite que contenham a mesma questão de direito controvertida. Porém, esta escolha de recursos representativos realizada pelo presidente ou vice-presidente do tribunal de origem não vincula o

${ }^{33}$ BRASIL. Lei $\mathbf{n}^{\mathbf{0}}$ 13.105. 16 de março de 2015. Institui o Código de Processo Civil.Disponível em <http://www.planalto.gov.br/ccivil_03/_Ato2015-2018/2015/Lei/L1310 5.htm> Acesso em: 07 nov. 2015.

${ }^{34}$ Ibidem. 
relator do tribunal ad quem, podendo o relator selecionar outros casos representativos. ${ }^{35}$

Após selecionados, o relator do tribunal destinatário proferirá decisão de afetação, na qual deverá estar contida principalmente e com precisão a questão de direito a ser submetida a julgamento, havendo vedação expressa no referido diploma quanto ao órgão decidir sobre questões alheias as que foram delimitadas na referida decisão. ${ }^{36}$

O prazo previsto para o julgamento dos RE e RESP múltiplos também é de 01 (um) ano; findo este prazo, os efeitos relativos ao seu não julgamento serão semelhantes aos institutos preteritamente estudados, ou seja, cessarão automaticamente, em todo o território nacional, a afetação e a suspensão dos processos, que retomarão seu curso normal. ${ }^{37}$

Nos julgamentos dos RE e RESP repetitivos o relator poderá lançar mão de consultas e manifestações de terceiros sobre a questão de direito debatida. Poderá solicitar ou admitir a manifestão de pessoas, órgãos e entidades que tenham interesse na controvérsia bem como fixar audiência pública para ouvir pessoas que tenham experiência e conhecimento sobre a matéria. ${ }^{38}$

O diploma é enfático ao determinar que o conteúdo do acórdão abrangerá a análise de todos os fundamentos da tese jurídica discutida, favoráveis ou contrários.

Com relação aos efeitos do acórdão proferido em sede de repetição do intituto ora analisado, o Código é claro em determinar que, sendo decididos os recursos afetados, os demais órgãos declararão prejudicados os recursos vindouros ou os decidirão aplicando a tese firmada no referido acórdão. ${ }^{39}$

Após a públicação do acórdão paradigma, o presidente ou vicepresidente do tribunal a quo negará seguimento aos recursos especiais ou extraordinários sobrestados na origem, se o acórdão recorrido coincidir com a orientação do tribunal superior. Ou seja, haverá um instrumento hábil disponível ao presidente ou vice-presidente do tribunal de justiça ou

\footnotetext{
${ }^{35}$ BRASIL. Lei $\mathbf{n}^{\circ}$ 13.105. 16 de março de 2015. Institui o Código de Processo Civil.Disponível em <http://www.planalto.gov.br/ccivil_03/_Ato20152018/2015/Lei/L13105.htm> Acesso em: 07 nov. 2015.

${ }^{36}$ Ibidem.

${ }^{37}$ Ibidem.

${ }^{38}$ Ibidem.

${ }^{39}$ Ibidem.
} 
tribunal regional federal para a eliminação na "fonte" de recursos repetitivos que contenham tese contrária à firmada preteritamente em acórdão paradigma proferidos nos tribunais superiores.

Uma última caracaterística importante contida no presente instituto é a de que sua desistência independe da anuência do réu, ainda que apresentada a contestação. ${ }^{40}$

\section{CRÍTICAS E DEFESAS À APLICAÇÃO DOS PRECEDENTES}

\subsection{CRÍTICAS À APLICAÇÃO DE PRECEDENTES}

No sistema positivista a partir da "concepção da lei", nas palavras de Neil Duxbury, com a aplicação da regra do precedente, é possível se extrair que a corte possa ampliar ou restringir o alcance dos precedentes nas situação do caso concreto, assim, o magistrado pode se envolver em "atividade legislativa", realizando uma função de produção normativa. ${ }^{41}$

Na linha de raciocínio de aplicação dos precedentes, para Neil Duxbury, o sistema positivista não possui meios para justificar sua vinculação obrigatória, pois a ideia de que os precedentes vinculam futuras autoridades somente será respeitada mediante uma construção de doutrina ou sanções estipuladas, as quais seriam aplicadas às autoridades que ignorassem os precedentes. ${ }^{42}$

Outra dificuldade para a aplicação de precedentes no Brasil está no temor da criação do direito por parte dos magistrados, assim

\footnotetext{
40 BRASIL. Lei $\mathbf{n}^{0}$ 13.105. 16 de março de 2015. Institui o Código de Processo Civil.Disponível em <http://www.planalto.gov.br/ccivil_03/_Ato2015-2018/2015/Lei/L1310 5.htm> Acesso em: 07 nov. 2015.

${ }^{41}$ ODAHARA, Bruno Periolo. Um rápido olhar sobre o stare decisis.Processos Coletivos. Revista Eletrônica. Volume 2. $3^{\circ}$ Trimestre. 01 jul 2011-30 set 2011. Disponível em: <http://www.processoscoletivos.net/revista-eletronica/edicoes-anteriores>. Acesso em: 02 set. 2015.

42 Ibidem.
} 
persistindo que o princípio da imparcialidade está calcado no desempenho da sua função meramente de "boca da lei". ${ }^{43}$

Para José Maria Rosa Tesheiner, a utilização de precedentes obrigatórios é "essencialmente autoritária, centralizadora e culturalmente empobrecedora". ${ }^{44}$

Há ainda o argumento de que o sistema de precedentes, por si só, não possui a capacidade de resolver problemas relativos à interpretação jurídica, pois o debate de teóricos em torno da indeterminação do direito no século XX se deu no bojo de um sistema de precedentes, ou seja, no commom law. ${ }^{45}$

Maximiliano já demonstrava crítica à conduta conveniente dos operadores do direito na invocação de precedentes judiciais no Brasil:

Em virtude da lei do menor esforço e também para assegurarem os advogados o êxito e os juízes inferiores a manutenção de suas sentenças, do que muitos se vangloriam, preferem, causídicos e magistrados, às exposições sistemáticas de doutrina jurídica os repositórios de jursprudência. Basta a consulta rápida a um índice alfabético para ficar um caso liquidado, com as razões na aparência documentadas cientificamente. Por isso, os repositórios de decisões em resumo, simples compilações, obtêm êxito esplêndido de livraria. ${ }^{46}$

O comentário acima exposto foi realizado no início do século $\mathrm{XX}$ sem se imaginar as facilidade eletrônicas ofertadas na atualidade. ${ }^{47}$

${ }^{43}$ ODAHARA, Bruno Periolo. Um rápido olhar sobre o stare decisis.Processos Coletivos. Revista Eletrônica. Volume 2. $3^{\circ}$ Trimestre. 01 jul 2011-30 set 2011. Disponível em: <http://www.processoscoletivos.net/revista-eletronica/edicoes-anteriores>. Acesso em: 02 set. 2015.

${ }^{44}$ RAATZ, Igor. Precedentes obrigatórios ou precedentes à brasileira?Revista Eletrônica. V.2 N.5. Mai 2012. Disponível em: <http://www.temasatuaisprocessocivil.com.br/e dicoes-anteriores/58-v2-n5-maio-de-2012/192-precedentes-obrigatorios-ou-precedentes-abrasileira>. Acesso em: 10 set. 2015.

45 Ibidem.

${ }^{46}$ RAMIRES, Maurício. Crítica à aplicação de precedentes no direito brasileiro. Porto Alegre. Livraria do Advogado. 2010. p. 43.

${ }^{47}$ Ibidem. 
Há argumentação de que a utilização do sistema de precedentes traz uma série de desvantagens ao sistema jurídico; são elas:

Obstáculo ao desenvolvimento do direito e ao surgimento de decisões adequadasàs novas realidades sociais, óbice à realização da isonomia substancial, violação do princípio da separação dos poderes, violação da independência dos juizes, violação do juiz natural e violação da garantia do acesso à justiça. ${ }^{48}$

Realizada a abordagem de algumas críticas para a não utilização da teoria de "precedentes", a seguir serão expostas as considerações favoráveis à sua aplicação.

\subsection{DEFESAS À APLICAÇÃO DE PRECEDENTES}

A permissão de que um órgão fracionáriode uma Corte prolate decisões contrárias firmadas pelo órgão especial ou pelo plenário da mesma Corte é um atentado contra a própria coerência do sistema. Igualmente nociva é a ideia de que magistrado singular continue a proferir decisões divergentes à jurisprudência pacificada do Tribunal ao qual esteja vinculado. ${ }^{49}$

Os princípios da imparcialidade e da independência dos magistrados além de serem relativos não podem ser confundidos. Ignorar propositadamente entendimento consolidado o afasta de suas legítimas atribuições desacreditando seu papel e o aproximando da arbitrariedade e irresponsabilidade. ${ }^{50}$

48 RAMOS, Vinícius Estefaneli. Teoria dos precedentes judiciais e sua eficácia no sistema brasileiro atual. Disponível em: <http://jus.com.br/artigos/24569/teoria-dosprecedentes-judiciais-e-sua-eficacia-no-sistema-brasileiro-atual>. Acesso em: 02 set. 2013.

49 LIMA, Tiago Asfor Rocha. Primeiras impressões sobre os precedentes judiciais no Projeto de Novo Código de Processo Civil. Revista de Informação Legislativa. V.48 N. 190. Abr/jun 2011. Disponível em: http://www2.senado.leg.br/bdsf/item/id/242959. Acesso em: 12 set. 2015 .

${ }^{50}$ Ibidem. 
Com a utilização da técnica de distinguishing há o sepultamento da ideia de que o juiz se tornará imobilizado diante de um sistemas de precedentes, preso a aplicá-lo ao caso concreto. Somente estará submetido a isso se preferir não exercer a função de motivar, de externar seus fundamentos ao decidir. ${ }^{51}$

Do mesmo modo há que salientar que as técnicas do overruling e overriding impedem a petrificação do sistema judiciário, portanto, do direito. Arejando o sistema como um todo e o mantendo atualizado, provendo-o de flexibilização. ${ }^{52}$

$\mathrm{O}$ uso dos precedentes vinculantes gera uma série de vantagens ao sistema jurídico, tais como: segurança jurídica, previsibilidade, igualdade, coerência, garantia da imparcialidade do magistrado, desestímulo à litigância, racionalização do duplo grau de jurisdição, razoável duração do processo e maior eficiência do judiciário. ${ }^{53}$

Apesar da atual função do magistrado no sistema brasileiro ser a do poder-dever de controlar a constitucionalidade da lei no caso concreto, este não devota respeito aos precedentes como ocorre no sistema do common law. ${ }^{54}$

Essa ausência de respeito aos precedentes no Brasil, deve-se à falácia de que a lei seria suficiente para garantir a certeza e segurança jurídica. ${ }^{55}$

O direcionamento das decisões por meio dos precedentes obrigatórios é um desestímulo à litigância, em virtude de que o jurisdicionado poderá realizar previamente uma reflexão sobre os prós e os contras de se levar uma demanda à apreciação do poder judiciário. ${ }^{56}$

\footnotetext{
${ }^{51}$ LOURENÇO, Haroldo. Precedente judicial como fonte do direito: algumas considerações sob a ótica do novo CPC. Revista Eletrônica. v.1. n.6. Dez 2011. Disponível em: $<\mathrm{http} / / / \mathrm{www}$.temasatuaisprocessocivil.com.br/edicoes-anteriores/53-v1-n-6-dezembro-de2011-/166-precedente-judicial-como-fonte-do-direito-algumas-consideracoes-sob-a-otica-donovo-cpc>. Acesso em: 08 set. 2015.

52 Ibidem.

53 RAMOS, Vinícius Estefaneli. Teoria dos precedentes judiciais e sua eficácia no sistema brasileiro atual. Disponível em: http://jus.com.br/artigos/24569/teoria-dosprecedentes-judiciais-e-sua-eficacia-no-sistema-brasileiro-atual. Acesso em 02 set2015.

${ }^{54}$ MARINONI, Luiz Guilherme. Precedentes Obrigatórios. 3.ed. rev atual. e ampliada. São Paulo: RT, 2013. p. 98.

55 Ibidem.

${ }^{56}$ Ibidem.
} 
Oriundo da previsibilidade também será o favorecimento de acordos entre as partes, pois estas saberão de antemão as vantagens e desvantagens que possuem, podendo objetivamente negociar as contravérsias. ${ }^{57}$

A combinação entre a razoável duração do processo e a economia processual, advindas do respeito aos precedentes terá como resultado a inevitável eficiência do Poder Judiciário, possuindo grande relevância em virtude da redução dos custos e do julgamento de forma tempestiva. $^{58}$

Verifica-se a inserção dos conceitos de ratio decidendi,obiter dicta e fundamentos determinantes, bem como a inclusão dos institutos de distinguish e overriling no novo código de processo civil, o que irá arejar o sistema como um todo.

E para a efetivação dos precedentes no ordenamento jurídico brasileiro, o legislador nacional inseriu, no novo diploma, instrumentos capazes de dirimir as divergências dos julgados entre tribunais e entre os órgãos fragmentários dentro dos próprios tribunais.

\section{CONSIDERAÇÕES FINAIS}

Os dois sistemas jurídicos hoje existentes, o civil law e o common law, são oriundos de circunstâncias políticas e culturais completamente diversas, o que levou à criação de sistemas jurídicos completamente opostos.

A inserção da técnica de utilização de precedentes no Brasil está inserida no artigo 926 e seguintes da Lei 13.105/15 que estabelece o novo Código de Processo Civil e traz os pressupostos para seu processamento. No caput do artigo em questão, verifica-se o estabelecimento da uniformização e estabilidade da jurisprudência.

No artigo 927, há a determinação de que os juízes e os tribunais deverão observar as decisões do Supremo Tribunal Federal (STF) em controle constitucional concentrado, os enunciados de súmula vinculante, os acórdãos em incidente de assunção de competência ou resolução de

\footnotetext{
57 MARINONI, Luiz Guilherme. Precedentes Obrigatórios. 3.ed. rev atual. e ampliada. São Paulo: RT, 2013. p. 180.

58 Ibidem. p. 187.
} 
demandas repetitivas e em julgamento de recurso extraordinário e especial repetitivos.

Outra constatação importante é a de que os tribunais a quo necessariamente deverão observar, em seus julgados, as decisões proferidas pelo Supremo Tribunal Federal, pelo Superior Tribunal de Justiça e pelos Tribunais Estaduais aos quais estejam vinculados, caracterizando assim verdadeiramente a técnica dos precedentes de uma forma vertical.

Verifica-se no novo Código, a possibilidade de modulações, ou seja, de alterações da jurisprudência pacificada, contudo há pressupostos para que esta modificação seja concretizada. Esta modulação terá que ser justificada de forma razoável, pois haverá reflexos na segurança jurídica do sistema como um todo.

Os que divergem de sua efetiva aplicação denotam que o magistrado poderá se envolver em uma atividade legislativa, infringindo dessa maneira o princípio da tripartição dos poderes. Apresenta-se a ausência de instrumentos efetivos que possam controlar a sua utilização, de modo que, enquanto não houver imposição de sanções aos magistrados que o ignorem, não haverá controle sobre sua efetiva aplicação.

No entanto, há posicionamentos favoráveis frente à aplicação do instituto. Entre as visões mais otimistas, os frutos positivos que a aplicação da técnica poderá trazer ao ordenamento jurídico brasileiro são: segurança jurídica, previsibilidade, igualdade, coerência, garantia da imparcialidade do magistrado, desestímulo à litigância, racionalização do duplo grau de jurisdição, razoável duração do processo e maior eficiência do judiciário.

\section{REFERÊNCIAS BIBLIOGRÁFICAS}

BRASIL. Lei $\mathbf{n}^{\mathbf{0}} \mathbf{1 3 . 1 0 5}$ de 16 de março de 2015. Institui o Código de Processo Civil. Disponível em <http://www.planalto.gov.br/ccivil_03/_Ato20152018/2015/Lei/L13105.htm> Acesso em: 07nov. 2015.

FRAGA, Vitor Galvão. O sistema do Common Law. Jus Navigandi, Teresina, ano 17, n. 3394, 16 out. 2012. Disponível em: <http://jus.com.br/revista/texto/22816>. Acesso em: 05 jul. 2015

LIMA, Tiago Asfor Rocha. Primeiras impressões sobre os precedentes judiciais no Projeto de Novo Código de Processo Civil. Revista de 
Informação Legislativa. v. 48, n. 190. Abr/Jun 2011. Disponível em: <http://www2.senado.leg.br/bdsf/item/id/242959>. Acesso em: 12 set. 2015.

LOURENÇO, Haroldo. Precedente judicial como fonte do direito: algumas considerações sob a ótica do novo CPC. Revista Eletrônica. v.1. n. 6. Dez 2011. Disponível em: $<$ http://www.temasatuaisprocessocivil.com.br/edicoesanteriores/53-v1-n-6-dezembro-de-2011-/166-precedente-judicialcomo-fonte-do-direito-algumas-consideracoes-sob-a-otica-donovo-cpc>. Acesso em: 08 set. 2015.

MANZELLO, André. Jurisprudência Lotérica. JusBrasil Notícias. Out 2015.

Disponível em <http://andrecm.jusbrasil.com.br/noticias/222840959/jurisprudenci a-loterica?ref=topic_feed $>$. Acesso em: 02 nov 2015.

MARINONI, Luiz Guilherme. Aproximação crítica entre as jurisdições de civil law e de common law e a necessidade de respeito aos precedentes no Brasil. [pdf.]. Disponível em: <http://www2.trf4.jus.br/trf4/upload/editor/rlp_Luis_Marinoni.pdf $>$. Acesso em: 13 abr. 2015.

. Precedentes Obrigatórios. 2. ed. São Paulo: RT, 2012. (cap. 1). Disponível em: <http://www2.trf4.jus.br/trf4/upload/editor/rlp_Luis_Marinoni.pdf $>$. Acesso em: 13 abr. 2015.

ODAHARA, Bruno Periolo. Um rápido olhar sobre o staredecisis. Processos Coletivos Revista Eletrônica, Porto Alegre, vol. 2, n. 3, 01 jul. 2011. Disponível em: $<$ http://www.processoscoletivos.net/revista-eletronica/25-volume2-numero-3-trimestre-01-07-2011-a-30-09-2011/132-um-rapidoolhar-sobre-o-stare-decisis>. Acesso em: 24 set. 2015

RAATZ, Igor. Precedentes obrigatórios ou precedentes à brasileira? Revista Eletrônica, v.2 n.5. Mai 2012. Disponível em: $<$ http://www.temasatuaisprocessocivil.com.br/edicoesanteriores/58-v2-n5-maio-de-2012/192-precedentes-obrigatoriosou-precedentes-a-brasileira>. Acesso em: 10 set. 2015.

RAMIRES, Mauricio. Crítica à aplicação de precedentes no Direito Brasileiro. Porto Alegre: Livraria dos Advogados, 2010.

RAMOS, Vinícius Estefaneli. Teoria dos precedentes judiciais e sua eficácia no sistema brasileiro atual. Disponível em: $<$ http://jus.com.br/artigos/24569/teoria-dos-precedentes-judiciais- 
e-sua-eficacia-no-sistema-brasileiro-atual>. Acesso em: 02 set. 2015. 